Military Technical College

Kobry El-Kobbah, Cairo, Egypt

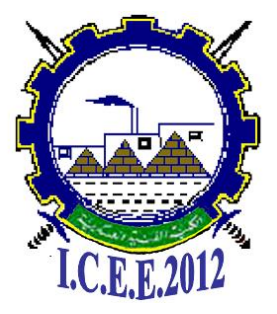

$6^{\text {th }}$ International Conference

on

Chemical \& Environmental

Engineering

29 -31 May, 2012.

\title{
CPTA-3
}

\section{APPLICATION OF GAS CHROMATOGRAPHY FOR THE ANALYSIS OF MALATHION BY FLAME PHOTOMETRIC DETECTOR}

\author{
A.Y. Kilany*, M. A. Elsayed*, M. S. Fayed*, M. K. Abd ElMegid*
}

\begin{abstract}
.
In this paper, Malathion as representative for organophosphorus pesticide was analysed by gas chromatography equipped with flame photometric detector (GC-FPD) (P-mode). The analysis was performed on HB-5, $30 \mathrm{~m}$ x $0.32 \mathrm{~mm}$ capillary column with a $0.25 \mu \mathrm{m}$ stationary film thickness using ultra pure nitrogen $(99.9999 \%)$ as a carrier gas at 25 psi constant pressure. The method successfully meets or even exceeds the minimum standards recommended in the American Society for Testing and Materials (ASTM) guidance. Sensitivity, minimum delectability, dynamic range, linear range and noise were measured. The linear ranges was $\left(8.8 \times^{10^{-9}}-3.9 \times^{10^{-8}}\right) \mathrm{gP} / \mathrm{s}$ and limit of detection was $\left(5.769 \times 10^{-11}\right)$ $\mathrm{gP} / \mathrm{s}$, while the dynamic range was (1-10500) $\mathrm{ppm}$. The relative standard deviation (RSD \%) was $2.6 \%(\mathrm{n}=5)$. The method is precise, reproducible and linear over a wide range of concentration. It can be recommended as a suitable method for the quantification of Malathion in cases of acute poisoning.
\end{abstract}

Keywords: Minimum Detectability, Dynamic Range, Linear Range, Noise, Organophosphorus pesticides, Malathion, GC/FPD.

\footnotetext{
*Egyptian Armed Forced
} 


\section{Introduction}

Organophosphates are organic esters of phosphoric acid, thiophosphoric acid and other phosphoric acids, which are widely used as insecticides and acaricides. Organophosphorus compounds exhibit a wide range of toxicity to mammals. They work on central nervous system inhibiting its normal function resulting in convulsions, paralysis and death, [1]. The use of pesticides in agriculture is necessary to combat a variety of pests that could destroy crops, and to improve the quality of the food produced. Agricultural use of pesticides plays a beneficial role in providing a plentiful, low-cost supply of high-quality fruits and vegetables. As a consequence of this use, the presence of residues in food that was critical elements of overall population health is unavoidable and pesticide residues in food is of great importance in the evaluation of food quality, [2].

Malathion is S-[1, 2-di(ethoxycarbonyl)ethyl] dimethyl phosphorothiolothionate which binds irreversibly to cholinesterase. The oral LD50 values for Malathion in laboratory rodents were $1000-10000 \mathrm{mg} / \mathrm{kg}$ of body weight, the observed differences probably being due to impurities, [3]. Malathion is an insecticide of relatively low human toxicity. The chemical structure of Malathion is shown in Figure 1, [1].

Pest control intensive agriculture involves treatment of crops (fruits, vegetables, cereals, etc.) Pre- and post-harvests with a variety of synthetic chemicals generically known as pesticides. Following the extraction/purification procedures, pesticide compounds are separated either by gas chromatography (GC) or liquid chromatography (LC), and then identified and quantified using different kinds of detection methods depending on the molecules to be analyzed. Electron-capture detection (ECD), flame photometric detection (FPD), nitrogen-phosphorus detection (NPD), fluorescence detection, and diode-array detection (DAD) were mostly used for pesticide identification and quantification, [4].

Descriptions of terms used in this paper are as follows:

The phosphorus sensitivity (response) of the FPD is the signal output per unit mass flow rate of P-atoms in a test substance in the carrier gas and was calculated as follows:

$\mathrm{S}_{\square}=\mathrm{A}_{\mathrm{i}} / \mathrm{m}_{\square}$

Where:

$\mathrm{S}_{\square}=$ phosphorus sensitivity (response), A.s/gP,

$\mathrm{A}_{\mathrm{i}}=$ integrated peak area, $\mathrm{A} \cdot \mathrm{s}$, and

$\mathrm{m}_{\square}=$ mass of P-atoms in the test substance, $\mathrm{gP}$.

Minimum Detectability for phosphorus is the mass flow rate of phosphorus atoms in the carrier gas that gives a detector signal equal to twice the peak to-peak noise level and calculated from the measured sensitivity and noise level values as follows:

$\mathrm{D}_{\square}=2 \mathrm{~N}$

Where:

$\mathrm{D}_{\square}=$ minimum detectability for phosphorus, $\mathrm{gP} / \mathrm{s}$,

$\mathrm{N}_{\square}=$ noise level in phosphorus mode, $\mathrm{A}$, and

$\mathrm{S}_{\square}=$ phosphorus sensitivity of the FPD, A.s/gP. 
Dynamic Range of the FPD is that range of mass flow rates of phosphorus or sulfur atoms over which a change in mass flow rate produces a change in detector output signal. Dynamic range was measured by Plotting the peak height $(\mathrm{H})$ versus $(\mathrm{m} \square \square)$ on (log- $\log$ ) graph paper. The upper limit of the dynamic range is the mass flow rate at which the slope is zero. The lower limit of the dynamic range is the mass flow rate which produces a detector signal that is twice the noise level (minimum detectability), the mass flow rate of phosphorus atoms was determined as follows:

$\mathrm{m} \square_{\square}=\mathrm{m}_{\square} / \mathrm{t}_{\square}$

Where:

$\mathrm{m} \square \square=$ mass flow rate of P-atoms in test substance, $\mathrm{gP} / \mathrm{s}$,

$\mathrm{m}_{\square}=$ mass of P-atoms in the test substance, gP, and

$\mathbf{t}_{\square}=$ peak width at $1 / 2$ of the maximum peak height, $\mathrm{s}$.

The linear range of the FPD in the phosphorus mode is the range of phosphorus atom mass flow rates over which the phosphorus sensitivity of the detector is constant to within $5 \%$ as determined from the linearity plot.

Noise is the amplitude expressed in amperes or Hertz of the baseline envelope which includes all random variations of the detector signal of the frequency on the order of $1 \mathrm{cycle} / \mathrm{min}$ or greater. This noise corresponds to the observed noise only. Both noise measurements and sensitivity measurements made under the same conditions, [5].

Precision may be defined as the concordance of a series of measurement of the same quantity. The mean deviation or the relative mean deviation is a measure of precision. In analytical chemistry one of the most common statistical terms employed is the stander deviation of a population of observation.

$$
s=\sqrt{\frac{\Sigma(x-\bar{x})^{2}}{n-1}}
$$

S......stander deviation

n.......number of values

More accurate measurement of the precision was known as the coefficient of variance (C.V.) or relative stander deviation (RSD).

$$
\text { c.v. }=(\mathbf{s x 1 0 0}) / \overline{\mathbf{x}}
$$

\section{Experimental Work}

\subsection{Reagents and solutions}

Malathion was purchased from Nasr Company for intermediate chemicals; purity $>95 \%$. Stock standard solutions were prepared by accurately weighing $0.3 \mathrm{~g}$ of pure material. Malathion was dissolved in pesticide-quality benzene and diluted to volume in a $25-\mathrm{mL}$ volumetric flask. If compound purity is certified at $96 \%$ or greater, the weight may be used without correction to calculate the concentration of the stock standard. Stock standard 
solutions were transferred into TFE-fluorocarbon-sealed screw-cap vials, stored at $4^{\circ} \mathrm{C}$ and protected from light. A set of test samples were Prepared by dilution from stock standard solutions covering a wide range of concentrations (1-10000) ppm of the test substance. These standards were then used for the validation of method (determination of limit of detection (LOD), limit of quantification (LOQ), recovery experiment and linearity experiment). A fixed volume $(1 \mu \mathrm{L})$ of each concentration of the test substance were injected, the height $(\mathrm{H})$ and integrated peak area $\left(\mathrm{A}_{\mathrm{i}}\right)$ of the resultant Gaussian or chromatographic peaks were measured. Frequently stock standard solutions were checked for signs of degradation or evaporation.

\subsection{Instrumentation and analysis condition}

Agilent, 7890A gas chromatograph, Autosampler (7693-series) with a split/ Splitless injector system and a flame photometric detection with phosphorus filter were used. Ultra pure nitrogen $(99.9999 \%)$ at 25 psi constant pressure was passed through a molecular sieve trap and an oxygen trap was used as the carrier gas. The injection port was held at $200{ }^{\circ} \mathrm{C}$ and used in the splitless mode. Separation was carried out on a HB-5, $30 \mathrm{~m}$ x $0.32 \mathrm{~mm}$ capillary column with a $0.25 \mu \mathrm{m}$ stationary film thickness (Agilent Technologies). In order to acquire the optimum conditions for Malathion determination, Operating conditions were as follows: detector temperature, $250{ }^{\circ} \mathrm{C}$ and hydrogen gas as detector gas was generated with hydrogen generator at a flow of $150 \mathrm{~mL} / \mathrm{min}$. The flow of zero air $(99.999 \%)$ for FPD was $110 \mathrm{~mL} / \mathrm{min}$ the air-to-fuel ratio was 0.73 . The column temperature was maintained at $60{ }^{\circ} \mathrm{C}$ for $1 \mathrm{~min}$ and then programmed at $20{ }^{\circ} \mathrm{C} / \mathrm{min}$ to $250{ }^{\circ} \mathrm{C}$, and held for $5 \mathrm{~min}$. The total analysis time was $15.5 \mathrm{~min}$. The volume of sample injected in splitless mode was $1.00 \mu \mathrm{L}$. Balance: Analytical, capable of accurately weighing to the nearest $0.0001 \mathrm{~g}$.

\subsection{Test Conditions:}

Since the FPD response can depend on sample compound structure as well as sample matrix, the test substance for the determination of FPD sensitivity may be selected in accordance with the expected application of the detector. The test substance should always be well defined chemically. When specifying the sensitivity of the FPD, the test substance applied must be stated, in the present study Malathion was stated. The measurement must be made at a signal level between 20 and 200 times greater than the noise level, [5]. The conditions under which the detector sensitivity is measured must be stated. This should include but not necessarily be limited to the following: Mode of operation (P-mode), Hydrogen flow rate (150) $\mathrm{mL} / \mathrm{min}$, Air or oxygen flow rate (110) $\mathrm{mL} / \mathrm{min}$, Carrier gas (Ultra pure nitrogen (99.9999\%), Detector temperature $250{ }^{\circ} \mathrm{C}$, Method of measurement.

\section{Results and Discussions}

Figure 3, Malathion chromatogram exhibits good separation and peak shape for all different concentration of (1-10500) ppm, the height $(\mathrm{H})$ and integrated peak area (Ai) of the resultant Gaussian or chromatographic peaks were measured. Under the optimal conditions, figure 2 the linearity for analysis of Malathion sample was evaluated with the measured peak area of the analyte against their concentrations. The method showed good linearity for all the selected compounds over the studied concentration range with correlation coefficient higher than $(\mathrm{R}=$ 0.9950). 


\subsection{Noise measurement}

Both noise measurements and sensitivity measurements made under the same conditions [5]. The measurement has been done in the range of Malathion retention time (8.9) minute. From figure 5, two parallel lines were drawing to form an envelope that encloses the random excursions of a frequency of approximately 1 cycle/min and greater. The distance perpendicular to the time axis between the parallel lines Measured and expressed the value as amperes of noise. The noise level equal $7.5 \times 10^{-10}$ A. Stander Values (ASTM) for noise, depending on the photomultiplier voltage, range from $\left(5 \mathrm{x}^{10^{-12}}: 5 \mathrm{x}^{10^{-10}} \mathrm{~A}\right)$.

\subsection{Sensitivity measurement}

Figure 4; show the relation between sensitivity and mass of P-atoms in the test substance. Stander Values (ASTM) for sensitivity: For phosphorus, 20 to $200 \mathrm{~A} \cdot \mathrm{s} / \mathrm{gP}$. These values will depend on photomultiplier voltage, [5]. The figure shows that:

Concentration (1-200) ppm the sensitivity is less than typical value of sensitivity (20-200) A.s/gP because the concentration is less than $(20-200)$ times the noise level.

Concentration (200-10500) ppm the sensitivity in the range of typical value (20-200) A.s/gP because it is a far from the noise level and a saturation has been reached from concentration (3500-10500) ppm (more than 22 times the noise level).

\subsection{Minimum detectability measurement}

From equation 2, (D $\left.\square=5.769 \mathrm{x}^{10^{-11}}\right) \mathrm{gP} / \mathrm{s}$, this value equal to concentration $0.7 \mathrm{ppm}$ Malathion. Figure 6 show that chromatogram of (1) ppm Malathion. The height of Malathion signal equals $17.1 \mathrm{x}^{10^{-10}} \mathrm{~A}$ this value more than twice the noise level (2.28).

Figure 7 show that chromatogram of (0.5) ppm Malathion the height of Malathion signal equal $\left(9.0 \mathrm{x}^{10^{-10}} \mathrm{~A}\right)$ this value equal (1.2) the noise level. Stander Values (ASTM) for phosphorus, $5 \times 10^{-13}$ to $5 \times 10^{-12} \mathrm{gP} / \mathrm{s}$.

\subsection{Limit of quantification (LOQ)}

For this study, the lower level where measurements became quantitatively meaningful was called the LOQ [7, 8]. LOQ was calculated to be equal (4) ppm Malathion. Figure 8, the height of Malathion signal equal $\left(70.5 \times \mathrm{x}^{10^{-10}} \mathrm{~A}\right)$ this value equal (10) the noise level.

\subsection{Dynamic range}

The lower limit of the dynamic range is the mass flow rate which produces a detector signal that is twice the noise level (1) ppm. The upper limit is the highest mass flow rate at which a slight further increase in mass flow rate will give an observable increase in detector signal at which the slope is zero. Figure 7 shows that dynamic range of FPD-P mode with Malathion range from (1-10500) ppm after concentration $10500 \mathrm{ppm}$ Malathion, a saturation level has been reached in the GC-Column with Malathion.

\subsection{Linear range}

Figure 7 show FPD Linearity Plot for the Phosphorus Mode with Malathion. Linear range for phosphorus equal $\left(8.8 \mathrm{x}^{10^{-9}}: 3.9 \mathrm{x}^{10^{-8}}\right) \mathrm{ngP} / \mathrm{s}$. this value corresponding to concentration (206-1187) ppm Malathion. 


\subsection{Precision}

Stander concentration (851.31) ppm injected 5 times as shown in figure 9. The coefficient of variance (C.V.) was calculated from equation (5). C.V. (RSD) $=2.6 \%$. Stander Values (ASTM) $20 \%$ RSD or less. These RSD values are better than those reported previously for similar work [6].

\section{Conclusion}

In conclusion, Analysis of Malathion samples showed the validity of Gas ChromatographyFlame Photometric Detector (P-mode) providing excellent separation and peak shape for Malathion. The method is precise, reproducible, simple, rapid, sensitivity, has a wide range of linearity and dynamic range over a wide range of analyte concentrations with correlation coefficient ( $\mathrm{R}=0.9950)$ and (RSD) $\square 3 \%$, and uses small volumes of solvents and samples, reducing the risk for human health and the environment. Besides, the results of this study show that the proposed method could be further applicable to determine the residues of different pesticides in environment. 


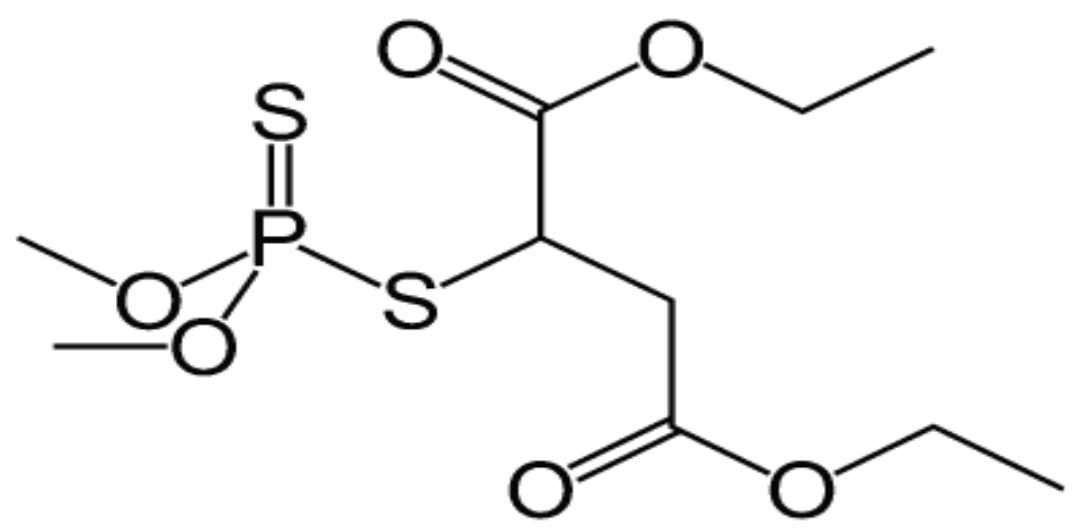

FIG. 1 the Chemical Structure of Malathion

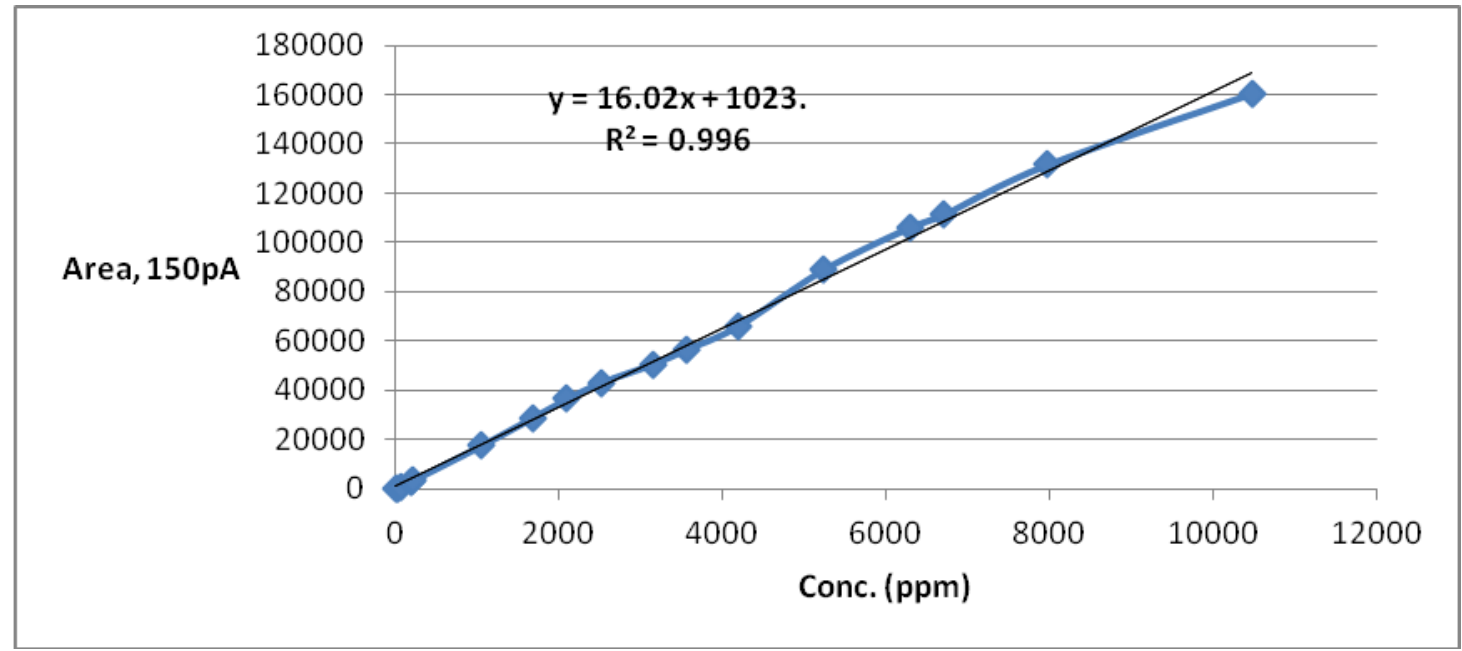

FIG.2 concentration of Malathion against area under the curve

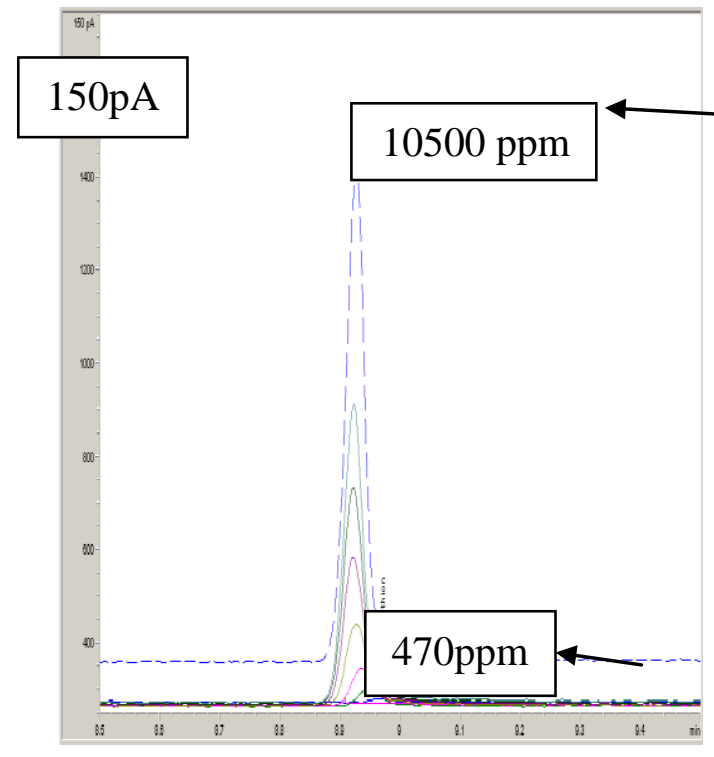

Time (min.)

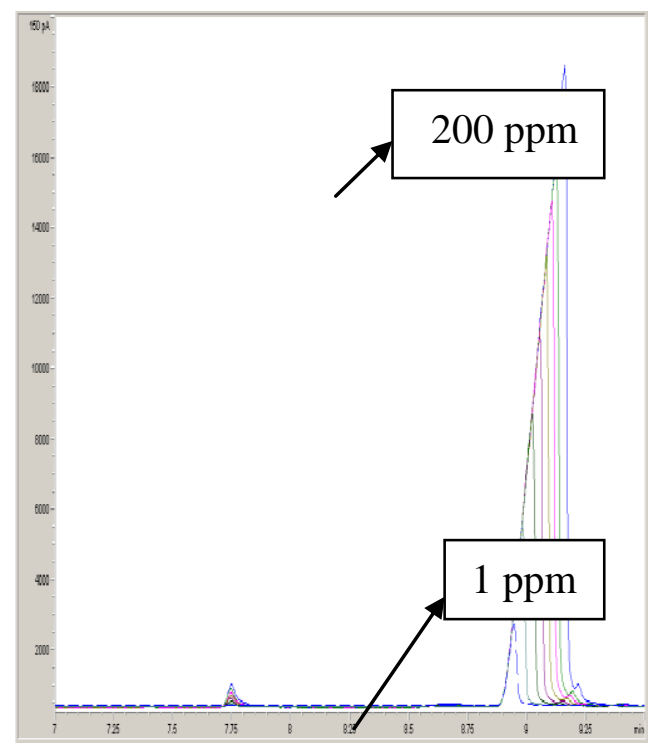

Time (min.)

FIG. 3 Peaks of Malathion with different concentration (GC-FPD-P mode) 


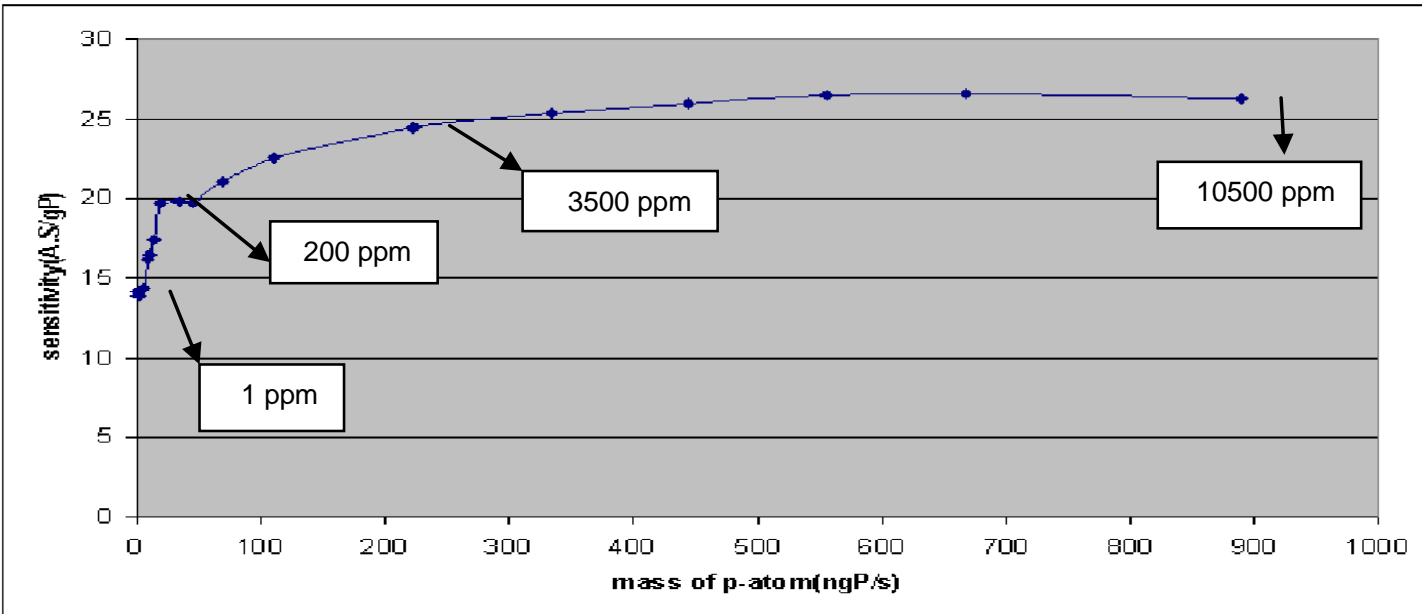

FIG. 4 Sensitivity of FPD against mass of P-atom

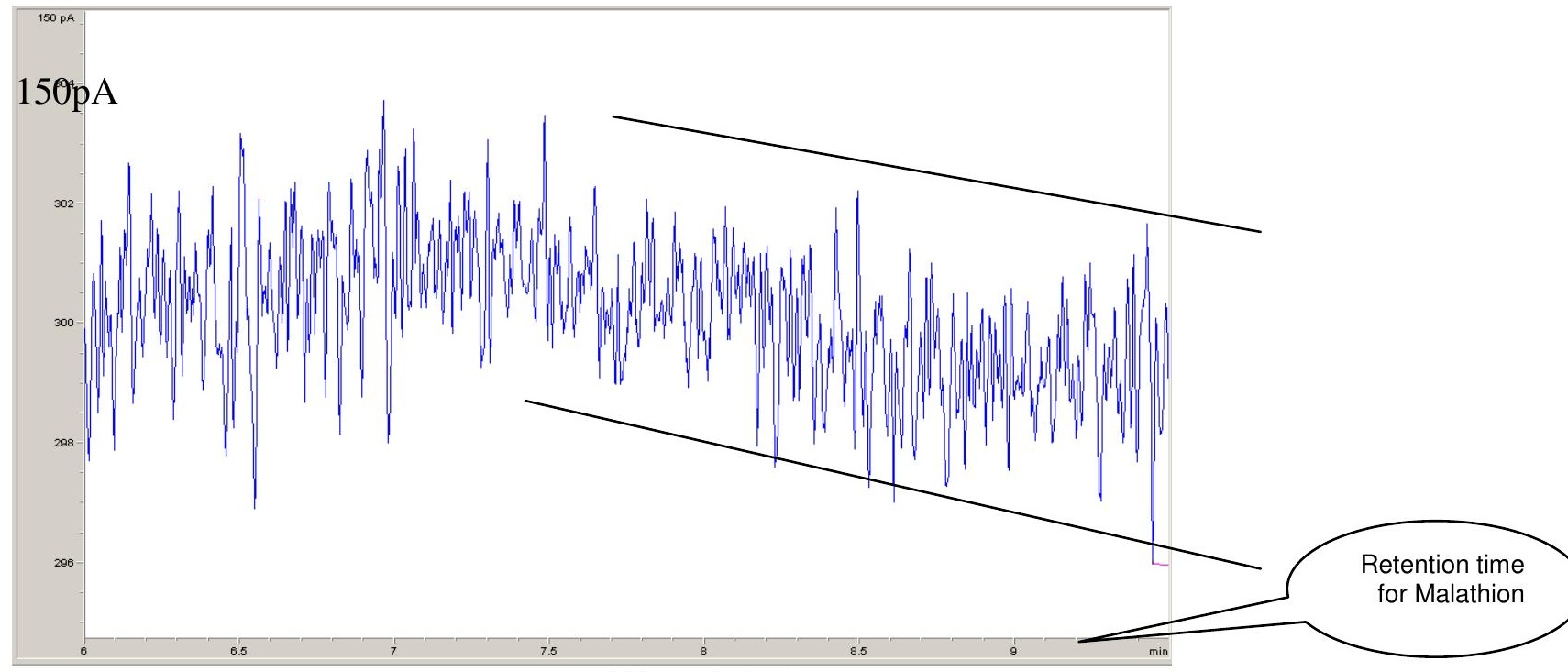

Time (min.)

FIG. 5 FPD Noise Level Measurement 


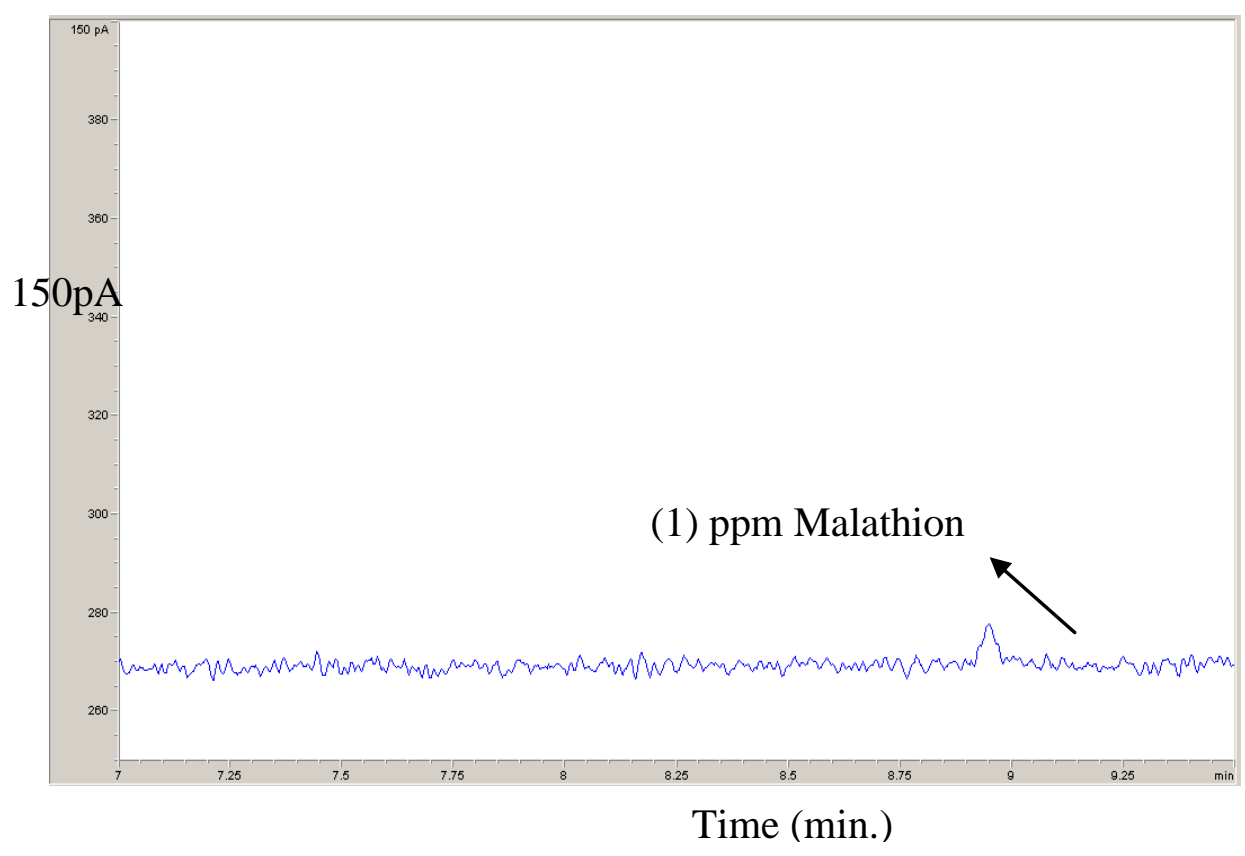

FIG.6 chromatogram of (1) ppm Malathion

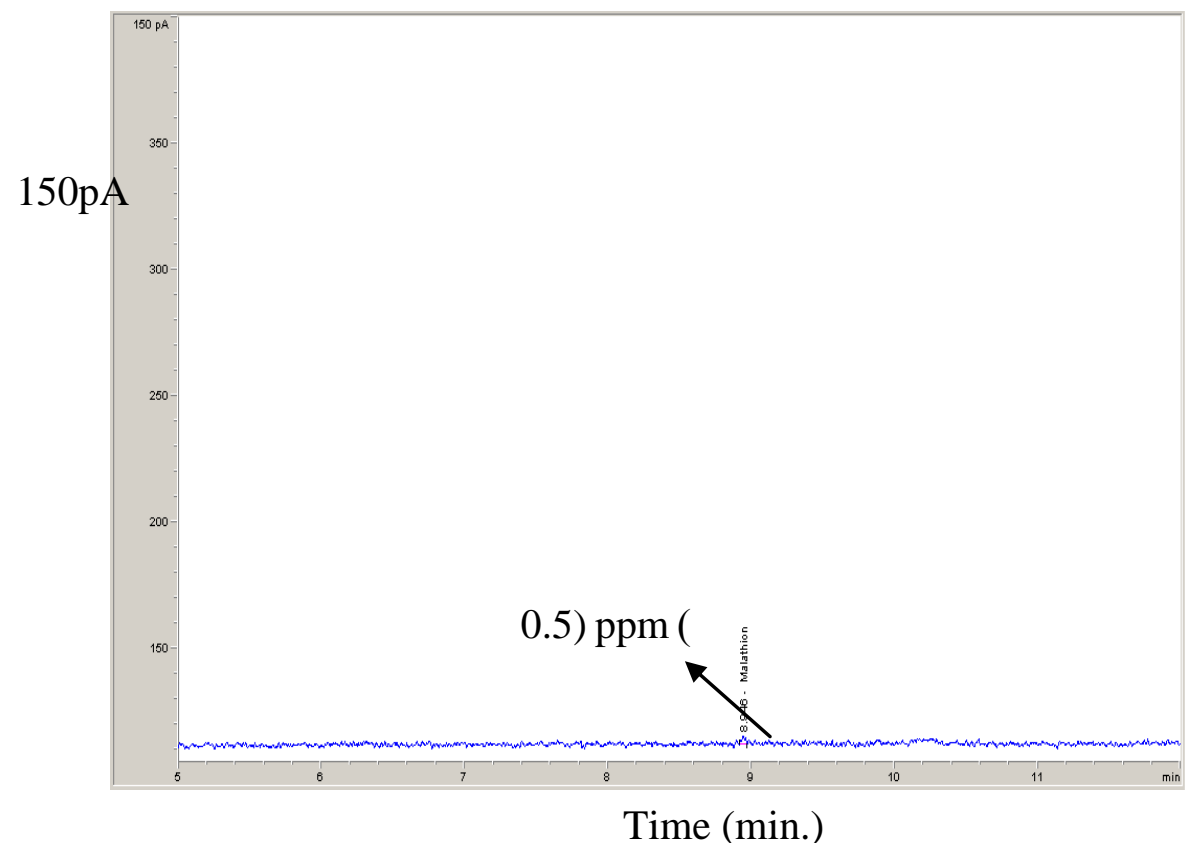

FIG.7 chromatogram of (0.5) ppm Malathion 


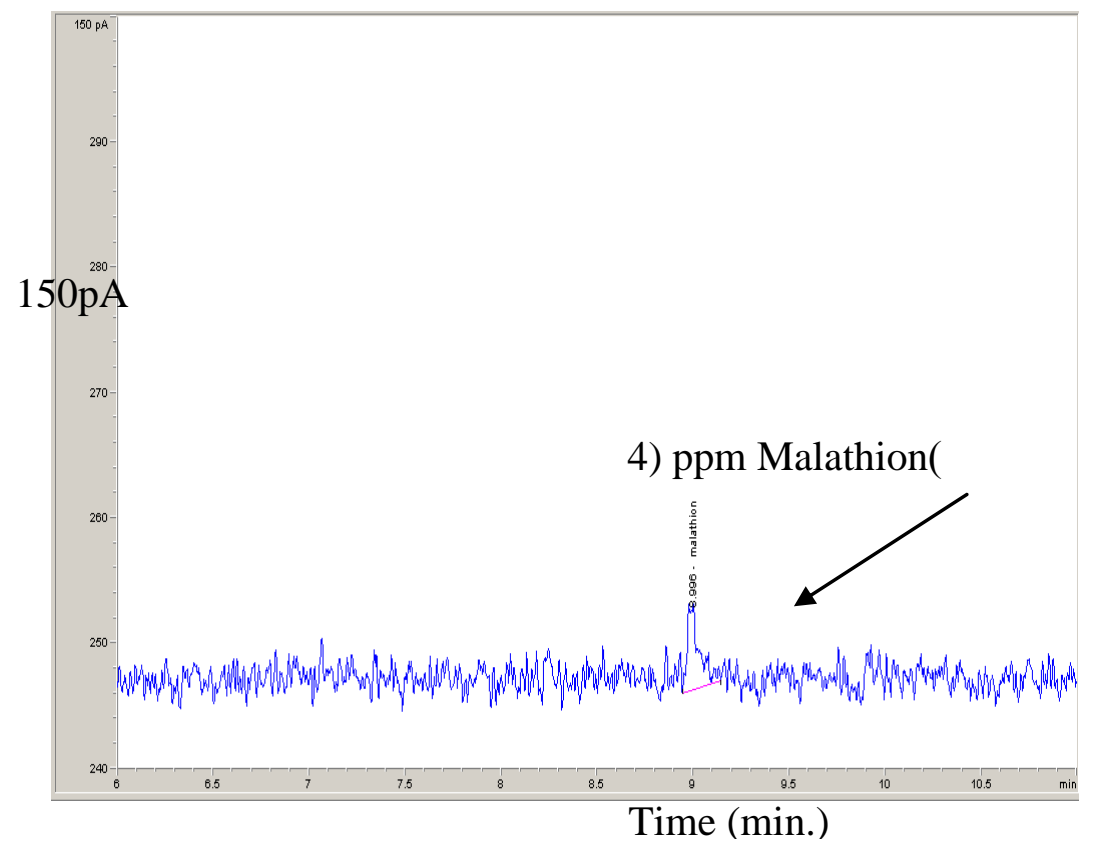

FIG.8 chromatogram of (4) ppm Malathion

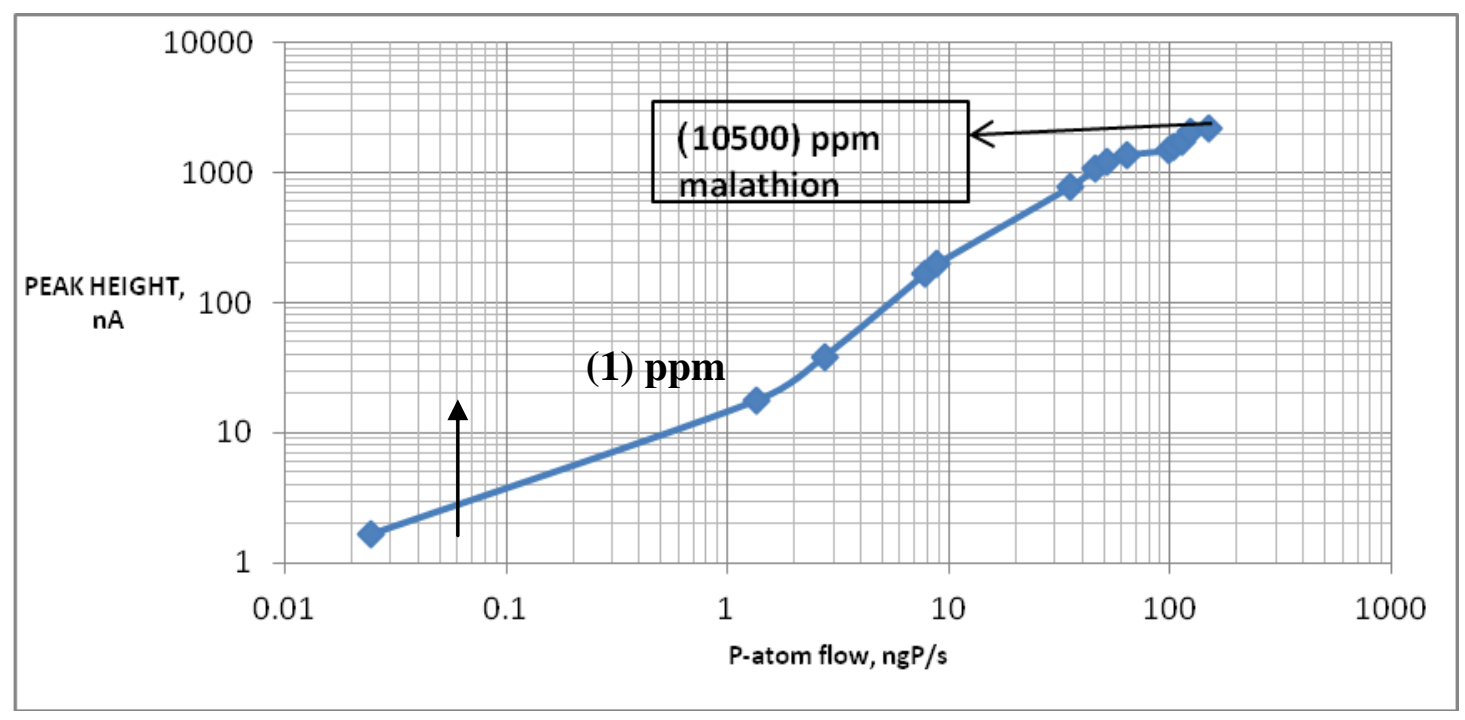

Fig. 9 Determine the Dynamic Range of an FPD in the Phosphorus Mode with Malathion 


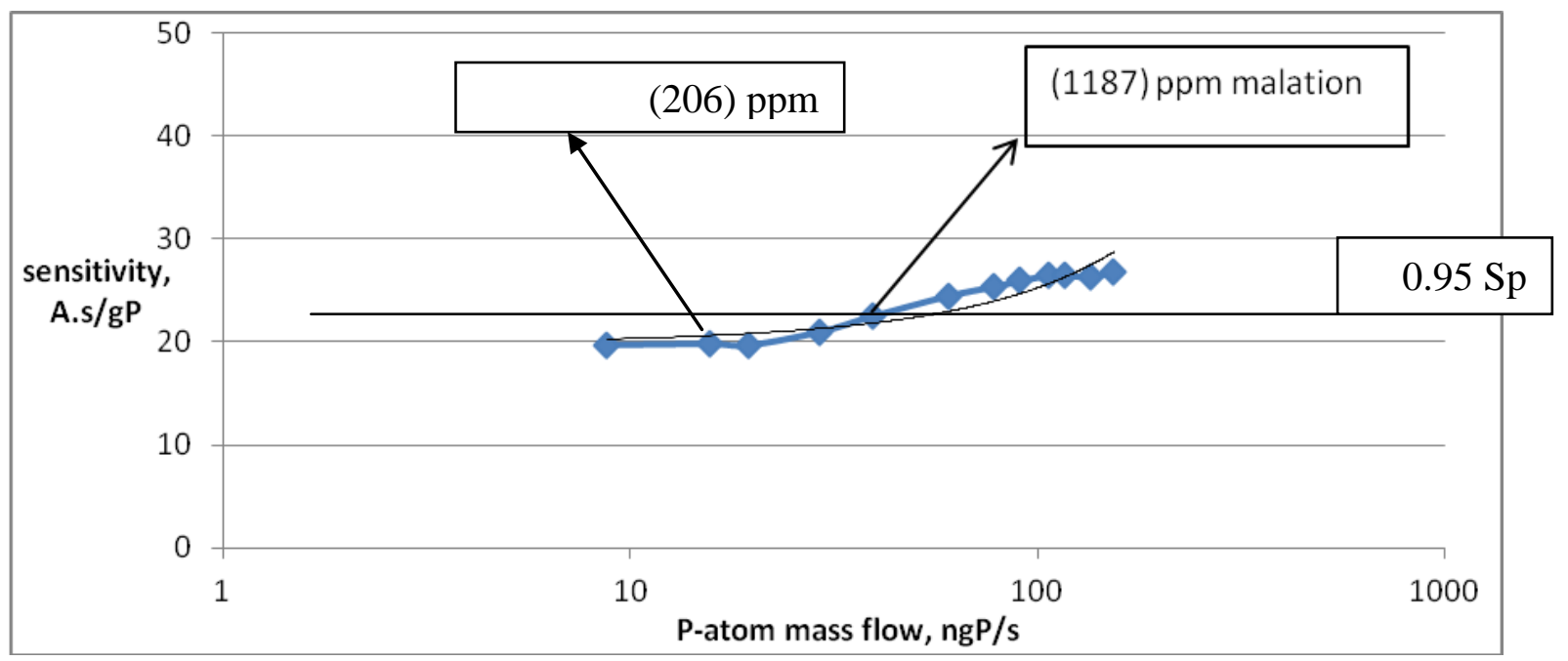

FIG. 8 FPD Linearity Plot for the Phosphorus Mode

Table 1. 5 injection of (851.31) ppm Malathion

\begin{tabular}{|c|c|}
\hline Injection & Area under the curve(150 p A.s) \\
\hline 1 & 13765.5 \\
\hline 2 & 13270.0 \\
\hline 3 & 12645.6 \\
\hline 4 & 13879.1 \\
\hline 5 & 13641.8 \\
\hline Mean & $\mathbf{1 3 4 4 0 . 4}$ \\
\hline
\end{tabular}

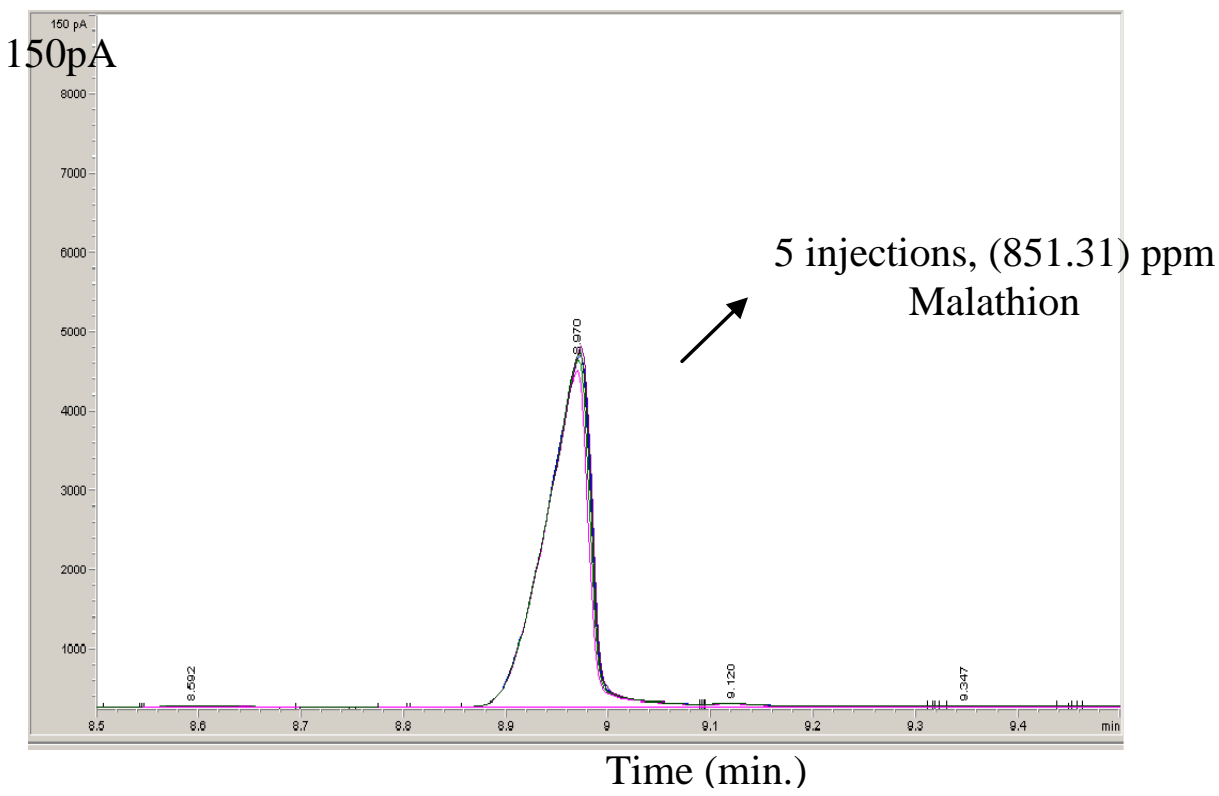

FIG.9 chromatogram of 5 injection (851.31) ppm Malathion 


\section{References}

[1] AYMAN A. GOUDA1 ALAA S. AMIN2 RAGAA EL SHEIKH1 MAGDA A. AKL, "sensitive spectrophotometric method for determination of some organophosphorus EWDWCD s pesticide in SAMPLES", Chemical Industry \& Chemical Engineering Quarterly 16 (1) 11-18 (2010)

[2] Goto, T., Ito, Y., Oka, H., Saito, I., Matsumoto, H., \& Nakazawa, H. "Simple and rapid determination of $\mathrm{N}$-methylcarbamate pesticides in citrus fruits byelectrospray ionization tandem mass spectrometry". Analytica Chimica Acta, 487, (2003).

[3] WHO, "Malathion in Drinking-water", WHO/SDE/WSH/03.04/103 English only, 2004.

[4] A. Navas Diaz, A. Garcia Pareja, F. Garcia Sanchez, "Analytical methods applied to the determination of pesticide residues in foods of animal origin". Sci. 49 (1997) 56.

[5] ASTM Standard E-840-95 (Reapproved 2000), "Practice for Using Flame Photo metric Detectors in GC", American Society for Testing and Materials, Philadelphia, PA, 1995.

[6] D.A. Lambropoulou, E. Psillakis, T.A. Albanis, N. Kalogerakis, Anal. Chim. Acta 516 (2004) 205. Laboratory Procedure Manual, CDC, Method No.: 11-OD, Organic Analytical Toxicology Branch, Division of Laboratory Sciences, CDC, National Center for Environmental Health, Atlanta, USA

[7] D.B. Barr, J.R. Barr, V.L. Maggio, R.D. Whitehead Jr., M.A. Sadowski, R.M.Whyatt, L.L. Needham, J. Chromatogr. B 778 (2002) 99 